\title{
Vertebral Osteotomies in Ankylosing Spondylitis -Comparison of Outcomes Following Closing Wedge Osteotomy versus Opening Wedge Osteotomy: A Systematic Review
}

\author{
Robert A. Ravinsky ${ }^{1}$ Jean-Albert Ouellet ${ }^{2,3}$ Erika D. Brodt ${ }^{4} \quad$ Joseph R. Dettori ${ }^{4}$
}

${ }^{1}$ Division of Orthopedic Surgery, Memorial University of Newfoundland, St. John's, Newfoundland, Canada

${ }^{2}$ Shriners Hospital Canada and Montreal Children's Hospital, Montreal, Quebec, Canada

3 McGill University Health Centre, Montreal General Hospital,

Montreal, Quebec, Canada

${ }^{4}$ Spectrum Research, Inc., Tacoma, Washington, United States

Evid Based Spine Care J 2013;4:18-29.
Address for correspondence Robert. A. Ravinsky, MD, CM, Division of Orthopedic Surgery, Memorial University of Newfoundland, Health Sciences Centre, H 1826, 300 Prince Philip Drive, St. John's, NL, Canada A1B 3V6 (e-mail: robert.ravinsky@mail.mcgill.ca).

\author{
Abstract \\ Keywords \\ - ankylosing spondylitis \\ - thoracolumbar \\ kyphotic deformity \\ - opening wedge \\ osteotomy \\ - closing wedge \\ osteotomy
}

Study Design Systematic review.

Study Rationale To seek out and assess the best quality evidence available comparing opening wedge osteotomy (OWO) and closing wedge osteotomy (CWO) in patients with ankylosing spondylitis to determine whether their results differ with regard to several different subjective and objective outcome measures.

Objective The aim of this study is to determine whether there is a difference in subjective and objective outcomes when comparing CWO and OWO in patients with ankylosing spondylitis suffering from clinically significant thoracolumbar kyphosis with respect to quality-of-life assessments, complication risks, and the amount of correction of the spine achieved at follow-up.

Methods A systematic review was undertaken of articles published up to July 2012. Electronic databases and reference lists of key articles were searched to identify studies comparing effectiveness and safety outcomes between adult patients with ankylosing spondylitis who received closing wedge versus opening wedge osteotomies. Studies that included pediatric patients, polysegmental osteotomies, or revision procedures were excluded. Two independent reviewers assessed the strength of evidence using the GRADE criteria and disagreements were resolved by consensus.

Results From a total of 67 possible citations, 4 retrospective cohorts (class of evidence III) met our inclusion criteria and form the basis for this report. No differences in Oswestry Disability Index, visual analog scale for pain, Scoliosis Research Society (SRS)-24 score, SRS-22 score, and patient satisfaction were reported between the closing and opening wedge groups across two studies. Regarding radiological outcomes following closing versus opening osteotomies, mean change in sagittal vertical axis ranged from 8.9 to $10.8 \mathrm{~cm}$ and 8.0 to $10.9 \mathrm{~cm}$, respectively, across three studies; mean change in lumbar received

October 20, 2012

accepted after revision

November 30, 2012 (c) 2013 Georg Thieme Verlag KG Stuttgart · New York
DOI http://dx.doi.org/ 10.1055/s-0033-1341604. ISSN 1663-7976. 
lordosis ranged from 36 to 47 degrees and 19 to 41 degrees across four studies; and mean change in global kyphosis ranged from 38 to 40 degrees and 28 to 35 degrees across two studies. Across all studies, overall complication risks ranged from 0 to $16.7 \%$ following CWO and from 0 to $23.6 \%$ following OWO.

Conclusion No statistically significant differences were seen in patient-reported or radiographic outcomes between CWO and OWO in any study. The risks of dural tear, neurological injury, and reoperation were similar between groups. Blood loss was greater in the closing wedge compared with the opening wedge group, while the risk of paralytic ileus was less. The overall strength of evidence for the conclusions is low.

\section{Study Rationale and Context}

A significant proportion of patients afflicted with ankylosing spondylitis (AS) may suffer from debilitating, progressive kyphosis of the thoracolumbar spine. ${ }^{1-6}$ Despite improving medical therapies ${ }^{7,8}$ and conservative treatment modalities, there still exist specific clinical indications for surgical correction of thoracolumbar kyphotic deformities (TLKDs) in this patient population. With regard to options for the surgical treatment of TLKDs, the two best described techniques are the closing wedge osteotomy (CWO) or pedicle subtraction osteotomy and the opening wedge osteotomy (OWO) or a modified Smith-Petersen osteotomy. ${ }^{9-12}$ However, there is a dearth of research comparing outcomes following OWO with CWO in patients with AS.

\section{Objectives}

To determine whether there is a difference in subjective and objective outcomes when comparing CWO and OWO in patients with AS with respect to quality-of-life assessments, complication risks, and the amount of correction of the spine achieved at follow-up.

\section{Materials and Methods}

Study Design: Systematic review.

Search: PubMed, Cochrane collaboration database, and National Guideline Clearinghouse databases; bibliographies of key articles.

Dates Searched: 1970 through July 15, 2012.

Inclusion Criteria: (1) Adults, (2) ankylosing spondylitis with kyphotic deformities of the spine at any level, and (3) comparison of CWO (i.e., pedicle subtraction osteotomy) versus OWO (i.e., Smith-Petersen osteotomy).

Exclusion Criteria: (1) Pediatric patients, (2) polysegmental osteotomy, and (3) revision procedures.

Outcomes: (1) Quality of life, (2) function, (3) pain, (4) patient satisfaction, (5) radiographic assessment of correction at final follow-up (e.g., sagittal vertical angle), and (6) complications. Analysis: Means and information on variation (e.g., standard deviation or range) for continuous variables were abstracted from the report as available and change scores calculated. The mean percent improvement in the outcome score from baseline at each given follow-up time was calculated by dividing the change score by the baseline score to get the total percent improvement. Complication risks were calculated by dividing the number of patients with a given complication by the total number of patients at risk for that complication. Pooling of data was not done due to concerns regarding heterogeneity of treatments and populations as well as study quality.

Overall Strength of Evidence: Risk of bias for individual studies was based on criteria set by The Journal of Bone and Joint Surgery, ${ }^{13}$ modified to delineate criteria associated with methodological quality and risk of bias based on recommendations from the Agency for Healthcare Research and Quality. ${ }^{14,15}$ The overall strength evidence across studies was based on precepts outlined by the Grading of Recommendations Assessment, Development and Evaluation (GRADE) Working Group ${ }^{16}$ and recommendations made by the Agency for Healthcare Research and Quality (AHRQ). ${ }^{14,15}$

\section{Results}

- From 67 citations, 22 articles underwent full-text review; four retrospective cohort studies (CoE III) met our inclusion criteria and form the basis for this report (-Fig. 1). Characteristics of each study are outlined in - Table 1. See online supplementary material for critical appraisal and a list of excluded articles.

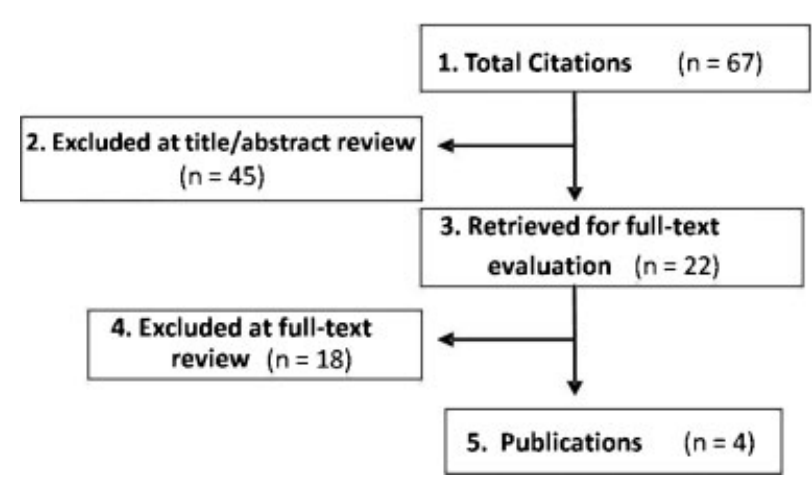

Fig. 1 Flow chart showing results of literature search. 


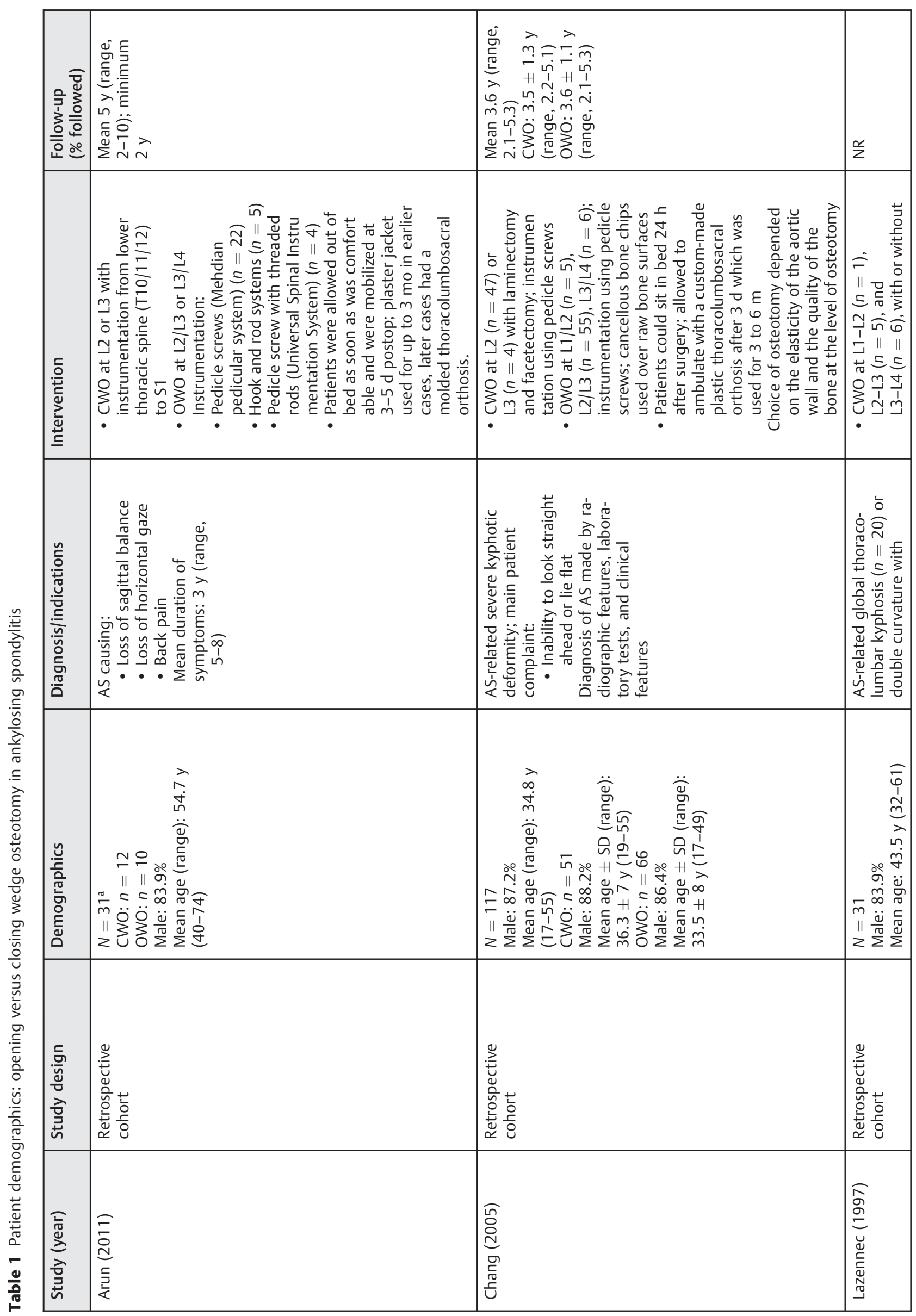




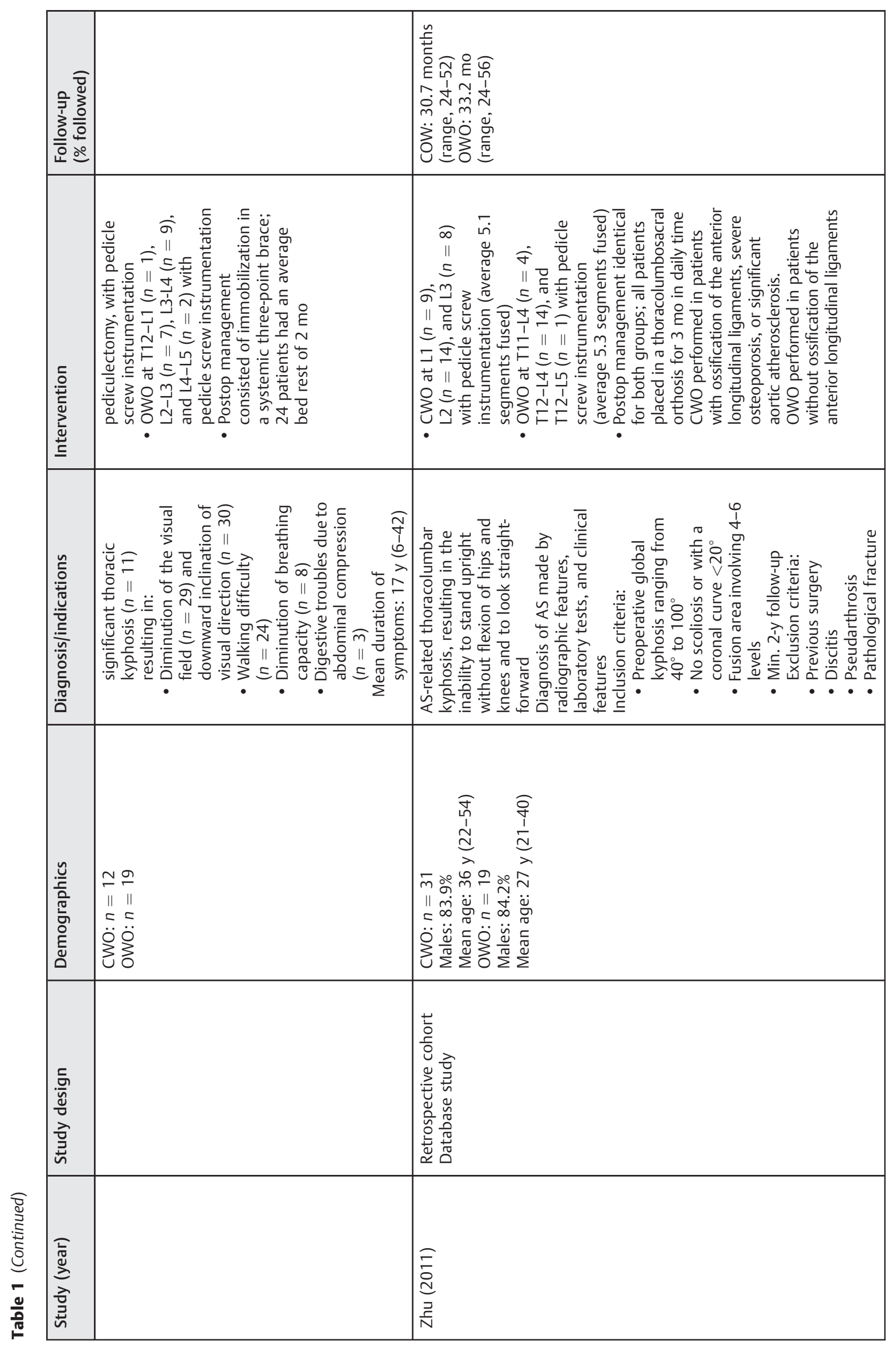

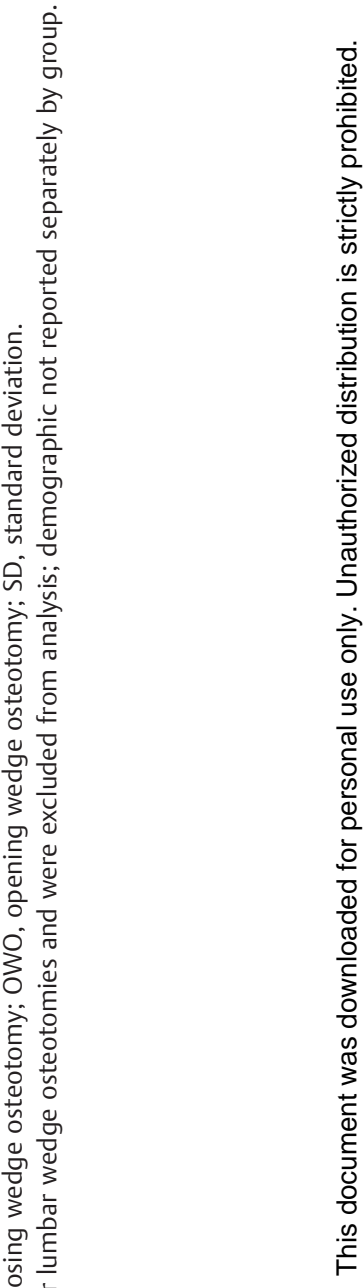




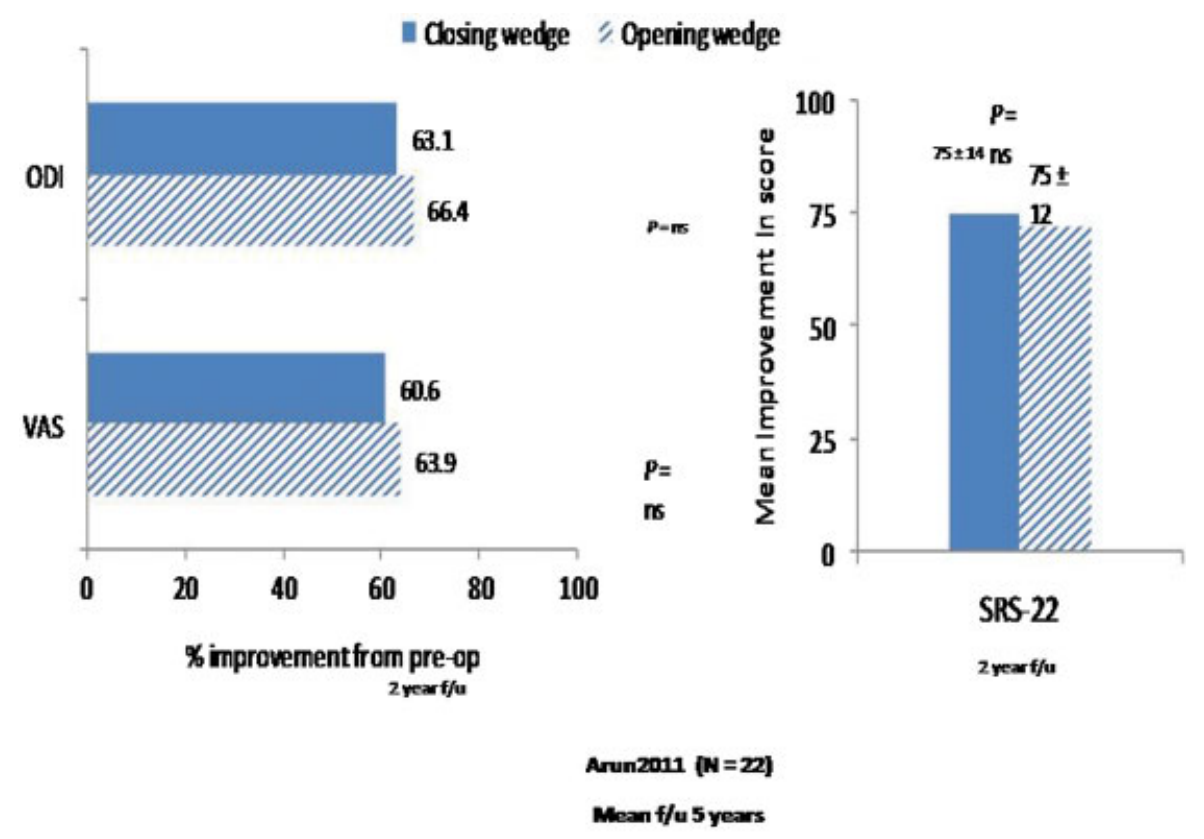

Fig. 2 Clinical outcomes including quality of life, function, and pain as reported by Arun et al (2011).

- The main indication for surgery across all studies was severe kyphotic deformity resulting in the inability to stand upright/lie flat or to look straight ahead.

- All procedures were performed using primarily pedicle screw instrumentation; one study used a hook-rod system and a pedicle screw with threaded rods system in onethird of their patients. ${ }^{17}$

\section{Patient-Reported Outcomes}

- There were no statistical differences between closing and OWO with respect to the Oswestry Disability Index (ODI), visual analog scale (VAS) for pain, or SRS-22 questionnaire scores at the 2-year follow-up in one study ( - Fig. 2). ${ }^{17}$ ODI scores improved a mean of 63.1 and $66.4 \%$ and VAS scores improved a mean of 60.6 and $63.9 \%$ in CWO and OWO, respectively. Mean improvement in total SRS-22 score was 75 in the closing group and 72 in the opening group.

- Chang et $\mathrm{al}^{18}$ reported average SRS-24 scores at a mean 3.6-year follow-up with no differences seen between the closing and opening osteotomy groups, respectively: questions 1 to $15,55.5$ versus 53.6 points; questions 16 to 24 , 42.3 versus 42.4 points ( $\mathbf{- F i g . ~ 3 )}$ ). The proportion of patients satisfied (i.e., would undergo same procedure) was almost identical between the groups, 88.2 and $87.9 \%$, respectively.

- A third study reported the proportion of patients who achieved "excellent functional results" (not defined) with those in the CWO group doing better than those in the OWO group: 50.0 versus $31.6 \%$, respectively (mean followup period not reported). ${ }^{19}$

\section{Radiological Outcomes}

-Table 2 summarizes the radiographic outcomes from included studies.

\section{Sagittal Vertical Axis}

- Across three studies, no differences were noted between treatment groups regarding the change in patients' sagittal vertical axis (SVA) over mean follow-up periods ranging from 2.6 to 5 years. ${ }^{17,18,20}$

- Mean change in SVA across the three studies ranged from 8.9 to $10.8 \mathrm{~cm}$ for the CWO group and 8.0 to $10.9 \mathrm{~cm}$ for the OWO group.

\section{Lumbar Lordosis}

- Lumbar lordosis at final follow-up was reported in all four studies with the mean change from preoperative to postoperative ranging from 36 to 47.4 degrees in the closing wedge group and from 19 to 41.1 degrees in the opening wedge group ${ }^{17-20}$; mean follow-up periods ranged from 2.6 to 5 years (follow-up not reported by one study).

\section{Global Kyphosis}

- The mean change in global kyphosis following CWO compared with OWO was reported by two studies with 2.6- and 5-year follow-up: 38 versus 28 degrees and 40 versus 35 degrees, respectively. ${ }^{17,20}$

\section{Other}

- One study reported the chin-brow vertical angle and the sacrohorizontal angle 5 years following surgery. In the CWO group, mean change from preoperative to postoperative was 15.8 and 20.1 degrees, respectively, and in the OWO group, 18.1 and 13.9 degrees, respectively. ${ }^{17}$

- A second study compared the closing and the opening wedge groups regarding change in thoracic kyphosis from preoperative to follow-up at 3.6 years: 3 degrees versus 2 degrees, respectively. ${ }^{18}$ 


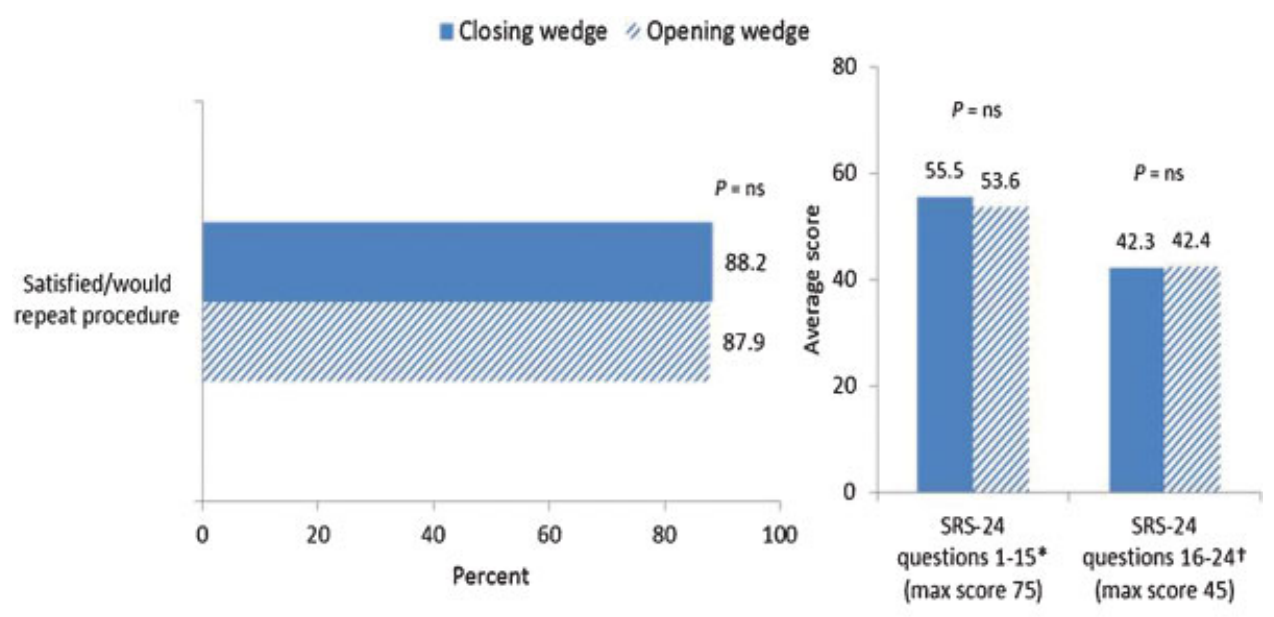

\section{Chang 2005 ( $N=117)$ \\ Mean $f / u$ 3.6 years}

\section{*Primarily regarding pain, general self-image, general function, and function-activity. †Primarily regarding function after surgery, self-imageafter surgery, and satisfaction with surgery.}

Fig. 3 Clinical outcomes including quality of life and patient satisfaction as reported by Chang et al (2005).

Table 2 Radiographic outcomes from included studies comparing closing wedge osteotomy with opening wedge osteotomy in ankylosing spondylitis

\begin{tabular}{|c|c|c|c|c|c|c|c|}
\hline \multirow[t]{2}{*}{ Outcome } & \multirow{2}{*}{$\begin{array}{l}\text { Mean F/U } \\
\text { (in years) }\end{array}$} & \multicolumn{3}{|c|}{ Closing wedge } & \multicolumn{3}{|c|}{ Opening wedge } \\
\hline & & Pre & Post & $\begin{array}{l}\text { Change }^{a} \\
\text { (pre-- } \\
\text { post) }\end{array}$ & Pre & Post & $\begin{array}{l}\text { Change }^{\mathrm{a}} \\
\text { (pre-post) }\end{array}$ \\
\hline \multicolumn{8}{|c|}{ Sagittal vertical axis (cm) } \\
\hline Arun (2011) & 5 & $14.5 \pm 3.9$ & $5.6 \pm 3.3$ & 8.9 & $13.6 \pm 3.4$ & $4.5 \pm 2.5$ & 9.1 \\
\hline Chang (2005) & 3.6 & $14.6 \pm 6.4$ & $6.9 \pm 4.1$ & 7.7 & $14.1 \pm 5.3$ & $6.1 \pm 2.9$ & 8.0 \\
\hline Zhu (2011) & 2.6 & $18.5 \pm 4.6$ & $7.7 \pm 5.5$ & 10.8 & $14.7 \pm 4.8$ & $3.8 \pm 3.1$ & 10.9 \\
\hline \multicolumn{8}{|c|}{ Lumbar lordosis (degrees) } \\
\hline Arun (2011) & 5 & $-15.4 \pm 3.5$ & $-53.7 \pm 4.1$ & 38.3 & $-12.6 \pm 3.0$ & $-31.6 \pm 11.3$ & 19 \\
\hline Chang (2005) & 3.6 & $-5 \pm 13$ & $31 \pm 16$ & 36 & $-3 \pm 11$ & $34 \pm 17$ & 37 \\
\hline Lazennec (1997) & NR & NR & NR & 47.4 & NR & NR & 41.1 \\
\hline Zhu (2011) & 2.6 & $-3.9 \pm 20.2$ & $-45.6 \pm 15.5$ & 41.7 & $-4.8 \pm 18.8$ & $-42.0 \pm 19.0$ & 37.2 \\
\hline \multicolumn{8}{|c|}{ Global kyphosis (degrees) } \\
\hline Arun (2011) & 5 & NR & NR & 38 & NR & NR & 28 \\
\hline Zhu (2011) & 2.6 & $73.7 \pm 23.6$ & $33.8 \pm 15.7$ & 39.9 & $64.6 \pm 25.6$ & $29.4 \pm 23.4$ & 35.2 \\
\hline \multicolumn{8}{|c|}{ Chin brow vertical angle (degrees) } \\
\hline Arun (2011) & 5 & $35.3 \pm 5.2$ & $19.5 \pm 1.5$ & 15.8 & $29.6 \pm 5.4$ & $11.5 \pm 2.5$ & 18.1 \\
\hline \multicolumn{8}{|c|}{ Thoracic kyphosis (degrees) } \\
\hline Chang (2005) & 3.6 & $54 \pm 13$ & $57 \pm 11$ & 3 & $57 \pm 16$ & $59 \pm 14$ & 2 \\
\hline \multicolumn{8}{|c|}{ Sacrohorizontal angle (degrees) } \\
\hline Arun (2011) & 5 & $9.3 \pm 5.2$ & $29.4 \pm 7.3$ & 20.1 & $10.9 \pm 2.4$ & $24.8 \pm 5.3$ & 13.9 \\
\hline
\end{tabular}

Abbreviations: F/U, follow-up; NR, not reported.

${ }^{a}$ Change scores reflect the absolute value of the difference between the preoperative and the postoperative scores. 
24 Vertebral Osteotomies in Ankylosing Spondylitis Ravinsky et al.

\section{Safety}

-Table 3 summarizes the safety outcomes from included studies.

\section{Perioperative Outcomes}

- Blood loss was reported by three studies and found to be higher during CWO compared with OWO. ${ }^{17,18,20}$

- In one of these studies, Chang et al also reported operative time that was longer in the closing wedge procedure than in the opening wedge: 217.7 versus 182.6 minutes. $^{18}$

\section{Complications}

- Overall, complication risks ranged from 0 to $16.7 \%$ in the CWO group and from 0 to $23.6 \%$ in the OWO group across the four studies. ${ }^{17-20}$

- The risks of dural tear in the closing versus the opening wedge groups, respectively, ranged from 0 to $8.3 \%$ versus from 6.1 to $21.1 \%$ across four studies. ${ }^{17-20}$

- Paralytic ileus occurred consistently less often in the CWO (0 to $5.9 \%$ ) versus the OWO (10.5 to $16.7 \%$ ) group as reported by two studies. ${ }^{18,20}$

- Across two studies, risk of reoperation ranged from 0 to $16.7 \%$ in the closing wedge group (epidural hematoma, extension of instrumentation) and from 15.8 to $20.0 \%$ in the opening wedge group (epidural hematoma, pseudarthrosis, secondary displacement, nonunion). ${ }^{17,19}$

- The risk of superficial infection following CWO ranged from 2.0 to $8.3 \%$ compared with 0 to $1.5 \%$ following OWO as reported by two studies. ${ }^{17,18}$

- Neurological injuries were reported by three studies and consisted of L2/L3 nerve root palsy (closing wedge 8.3\% vs. opening wedge $10.0 \%),{ }^{17}$ transient radiculopathy (5.9 vs. $4.5 \%$, respectively), ${ }^{18}$ and nerve root injury (9.7 vs. $5.3 \%$, respectively). ${ }^{20}$

\section{Clinical Guidelines}

None found.

\section{Evidence Summary}

The overall strength of evidence evaluating CWO compared with OWO with respect to patient-reported outcomes is very low; that is, any effect estimate is uncertain (-Table 4). Regarding radiographic outcomes, the overall strength of evidence is low, meaning we have low confidence that the evidence reflects the true effect and that further research is likely to change the confidence in the estimate of effect and likely to change the estimate. With respect to safety, the overall strength of evidence regarding blood loss, dural tear, paralytic ileus, and neurological injury is low; for reoperation, very low.

\section{Illustrative Case}

A 45-year-old woman with known ankylosing spondylitis (-Fig. 4), previously suffering from kyphoscoliosis with
Table 3 Safety outcomes from included studies comparing closing wedge osteotomy with opening wedge osteotomy in ankylosing spondylitis

\begin{tabular}{|c|c|c|}
\hline \multirow[t]{2}{*}{ Perioperative outcomes } & Closing wedge & Opening wedge \\
\hline & Mean \pm SD & Mean \pm SD \\
\hline \multicolumn{3}{|l|}{ Blood loss (\% of EBV) } \\
\hline Arun (2011) & $28 \pm 4.5$ & $15 \pm 11^{\mathrm{a}}$ \\
\hline \multicolumn{3}{|l|}{ Estimated blood loss (mL) } \\
\hline Chang (2005) & $1914.5 \pm 718.9$ & $1101 \pm 611.1$ \\
\hline Zhu (2011) & 1740 & 950 \\
\hline \multicolumn{3}{|l|}{ Operative time (min) } \\
\hline Chang (2005) & $217.7 \pm 61.6$ & $182.6 \pm 63.7$ \\
\hline Complications & $\%(n / N)$ & $\%(n / N)$ \\
\hline \multicolumn{3}{|l|}{ Dural tear } \\
\hline Arun (2011) & $8.3(1 / 12)$ & $20.0(2 / 10)$ \\
\hline Chang (2005) & $5.9(3 / 51)$ & $6.1(4 / 66)$ \\
\hline Lazennec (1997) & $0(0 / 12)$ & $21.1(4 / 19)$ \\
\hline Zhu (2011) & $3.2(1 / 31)$ & $10.5(2 / 19)$ \\
\hline \multicolumn{3}{|l|}{ Paralytic ileus } \\
\hline Chang (2005) & $5.9(3 / 51)$ & $16.7(11 / 66)$ \\
\hline Zhu (2011) & $0(0 / 31)$ & $10.5(2 / 19)$ \\
\hline \multicolumn{3}{|l|}{ Superficial infection } \\
\hline Arun (2011) & $8.3(1 / 12)$ & $0(0 / 10)$ \\
\hline Chang (2005) & $2.0(1 / 51)$ & $1.5(1 / 66)$ \\
\hline \multicolumn{3}{|l|}{ Reoperation } \\
\hline Arun (2011) & $16.7(2 / 12)^{\mathbf{b}}$ & $20.0(2 / 10)^{c}$ \\
\hline Lazennec (1997) & $0(0 / 12)$ & $15.8(3 / 19)^{\mathrm{d}}$ \\
\hline \multicolumn{3}{|l|}{ L2/L3 nerve root palsy } \\
\hline Arun (2011) & $8.3(1 / 12)$ & $10.0(1 / 10)$ \\
\hline \multicolumn{3}{|l|}{ Transient radiculopathy } \\
\hline Chang (2005) & $5.9(3 / 51)$ & $4.5(3 / 66)$ \\
\hline \multicolumn{3}{|l|}{ Nerve root injury } \\
\hline Zhu (2011) & $9.7(3 / 31)$ & $5.3(1 / 19)$ \\
\hline \multicolumn{3}{|l|}{ Aortic injury } \\
\hline Arun (2011) & $0(0 / 12)$ & $10.0(1 / 10)$ \\
\hline \multicolumn{3}{|l|}{ Intraoperative death } \\
\hline Arun (2011) & $0(0 / 12)$ & $10.0(1 / 10)^{\mathrm{e}}$ \\
\hline \multicolumn{3}{|l|}{ Pneumonia } \\
\hline Chang (2005) & $2.0(1 / 51)$ & $3.0(2 / 66)$ \\
\hline \multicolumn{3}{|l|}{ Nonunion/rod broken } \\
\hline Chang (2005) & $0(0 / 51)$ & $4.5(3 / 66)$ \\
\hline \multicolumn{3}{|l|}{ Lack of solid fixation } \\
\hline Lazennec (1997) & $8.3(1 / 12)^{f}$ & $21.1(4 / 19)^{g}$ \\
\hline \multicolumn{3}{|l|}{ Distal screw loosening } \\
\hline Chang (2005) & $5.9(3 / 51)$ & $1.5(1 / 66)$ \\
\hline \multicolumn{3}{|l|}{ Adjacent segment kyphosis } \\
\hline Chang (2005) & $5.9(3 / 51)$ & $3.0(2 / 66)$ \\
\hline
\end{tabular}


Table 3 (Continued)

\begin{tabular}{|c|l|l|}
\hline Perioperative outcomes & Closing wedge & Opening wedge \\
\cline { 2 - 3 } & Mean \pm SD & Mean \pm SD \\
\hline Anterior translation of the caudal segment of the spine \\
\hline Lazennec (1997) & $0(0 / 12)$ & $23.6(5 / 19)$ \\
\hline
\end{tabular}

Abbreviations: EBV, estimated blood volume; SD, standard deviation. axcluding outlier 99\% in one case.

bTo include reoperation for epidural hematoma and extension of instrumentation.

'To include reoperation for epidural hematoma and pseudarthrosis.

${ }^{\mathrm{d}}$ To include reoperation for secondary displacement in two cases and nonunion in one.

eSame patient with an aortic injury. Opening wedge osteotomy performed at same level as a fracture sustained a few years prior; brittle bone broke off creating a sharp spike, which caused aortic injury and catastrophic bleed.

fIn an elderly patient with poor bone quality.

${ }^{g}$ Early cases, when long, semi-rigid fixation was used. marked kyphosis in the thoracic spine, suffered from chronic back and leg pain. Progressive worsening of both sagittal and coronal balance secondary to her deformity required retroversion of the pelvis to compensate. Furthermore, this patient suffered from loss of horizontal gaze due to the kyphotic component of her deformity. Sagittal balance and coronal balance were corrected surgically by performing an asymmetric L3 OWO with subsequent pedicle screw internal fixation (-Figs. 5-7). At follow-up, horizontal gaze and sagittal balance were restored. At 4-year follow-up, patient remains unchanged and does not need pain medication.

\section{Discussion}

The study has the following limitations:

1. The majority of studies had small sample sizes.

2. Heterogeneity of clinical outcome measures and follow-up periods made comparisons across studies difficult.

Table 4 Summary of strength of evidence

\begin{tabular}{|c|c|c|c|c|c|}
\hline & $\begin{array}{l}\text { Strength of } \\
\text { evidence }\end{array}$ & Conclusions/comments & Baseline & $\begin{array}{l}\text { Upgrade } \\
\text { (levels) }\end{array}$ & $\begin{array}{l}\text { Downgrade } \\
\text { (levels) }\end{array}$ \\
\hline \multicolumn{6}{|c|}{ Patient-reported outcomes } \\
\hline $\begin{array}{l}\text { ODI } \\
\text { VAS pain } \\
\text { SRS questionnaire } \\
\text { Patient satisfaction }\end{array}$ & Very low & $\begin{array}{l}\text { - Results of all patient- } \\
\text { reported outcomes were } \\
\text { similar between the CWO } \\
\text { and OWO groups across two } \\
\text { retrospective cohort studies } \\
\text { with follow-up ranging from } \\
2 \text { to } 5 \text { y }\end{array}$ & Low & & $\begin{array}{l}\text { Inconsistency } \\
\text { of results (1) }\end{array}$ \\
\hline \multicolumn{6}{|c|}{ Radiographic outcomes } \\
\hline $\begin{array}{l}\text { SVA } \\
\text { Lumbar lordosis } \\
\text { Global kyphosis }\end{array}$ & Low & $\begin{array}{l}\text { - No statistically significant } \\
\text { differences were reported in } \\
\text { any radiographic outcome } \\
\text { between the two treatment } \\
\text { groups across four retro- } \\
\text { spective cohorts with mean } \\
\text { follow-up periods ranging } \\
\text { from } 2.6 \text { to } 5 \text { y (follow-up } \\
\text { not reported by one study) }\end{array}$ & Low & & \\
\hline \multicolumn{6}{|l|}{ Safety } \\
\hline Blood loss & Low & $\begin{array}{l}\text { Blood loss was greater in the } \\
\text { closing wedge compared } \\
\text { with the opening wedge } \\
\text { group across three retro- } \\
\text { spective cohorts }\end{array}$ & Low & & \\
\hline Dural tear & Low & $\begin{array}{l}\text { - No statistically significant } \\
\text { differences between groups } \\
\text { were reported in the risk of } \\
\text { dural tear across four retro- } \\
\text { spective cohorts }\end{array}$ & Low & & \\
\hline Paralytic ileus & Low & $\begin{array}{l}\text { - The risk of paralytic ileus was } \\
\text { less in the closing wedge vs. } \\
\text { the opening wedge group } \\
\text { across two retrospective co- } \\
\text { horts: } 5.9 \text { vs. } 16.7 \% \text { and } 0 \text { vs. } \\
10.5 \%\end{array}$ & Low & & \\
\hline
\end{tabular}


Table 4 (Continued)

\begin{tabular}{|l|l|c|l|l|l|}
\hline & $\begin{array}{l}\text { Strength of } \\
\text { evidence }\end{array}$ & Conclusions/comments & Baseline & $\begin{array}{l}\text { Upgrade } \\
\text { (levels) }\end{array}$ & $\begin{array}{l}\text { Downgrade } \\
\text { (levels) }\end{array}$ \\
\hline Reoperation & Very low & $\begin{array}{l}\text { - The risk of reoperation in the } \\
\text { closing wedge vs. the } \\
\text { opening wedge group varied } \\
\text { across two retrospective } \\
\text { cohorts: (0-20.0\%) }\end{array}$ & Low & $\begin{array}{l}\text { Imprecision of } \\
\text { effect estimates (1) }\end{array}$ \\
\hline Neurological injury & Low & $\begin{array}{l}\text { - The risks of transient radi- } \\
\text { culopathy, nerve root injury, } \\
\text { and L2/L3 nerve palsy were } \\
\text { similar in the closing wedge } \\
\text { when compared with the } \\
\text { opening wedge group across } \\
\text { three retrospective cohorts } \\
\text { (range, 5-10\%) }\end{array}$ & Low & & \\
\hline
\end{tabular}

Abbreviations: CWO, closing wedge osteotomy; OWO, open wedge osteotomy; ODI, Oswestry Disability Index; SRS, Scoliosis Research Society; SVA, sagittal vertical axis; VAS, visual analog scale.

Baseline quality: High = majority of articles Level I/II. Low = majority of articles Level III/IV. Upgrade: Large magnitude of effect (1 or 2 levels); dose response gradient (1 level).

Downgrade: Inconsistency of results (1 or 2 levels); indirectness of evidence (1 or 2 levels); imprecision of effect estimates (1 or 2 levels).

3. All studies were class of evidence III.

4. Choice of osteotomy depended on predetermined patient characteristics (e.g., significant aortic atherosclerosis, severe osteoporosis, ossification of the longitudinal ligaments) in two studies resulting in potential confounding by indication in these cases. ${ }^{18,20}$

5. One study used historical controls. Therefore, patients in the treatment group were potentially subject to changes in supportive care associated with secular trend. ${ }^{19}$
- This study sought to demonstrate improved outcomes in one of the two techniques; overall, however, the results of this systematic review demonstrate nonsuperiority of one technique over the other.

- Technical proficiency in both surgical techniques demands subspecialized training in spine surgery and substantial operative experience. It may be inferred that in the technically proficient surgeon, either procedure stands a
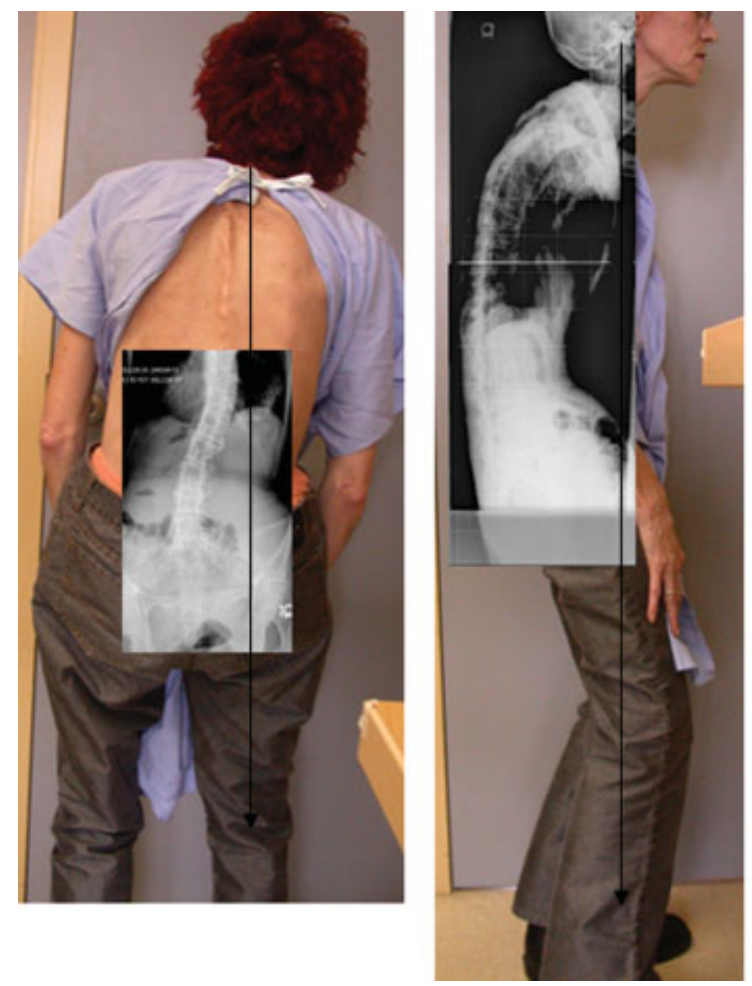

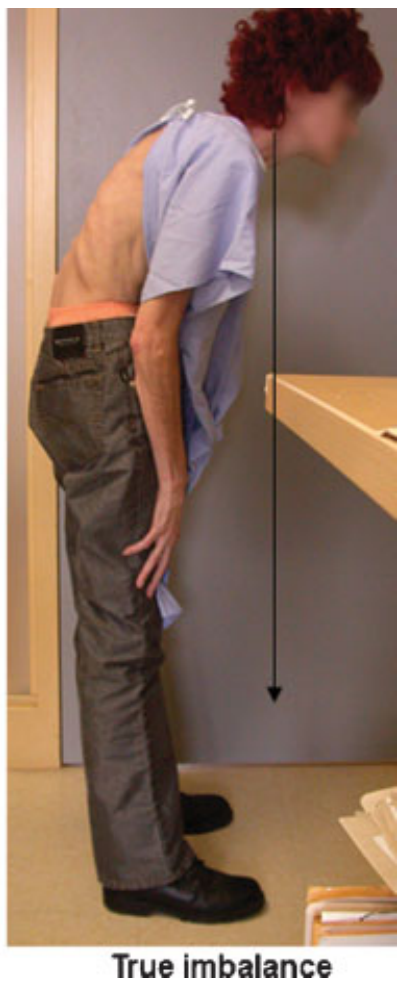

True imbalance

Fig. 4 A 45-year-old woman with a fixed coronal and sagittal spinal imbalance suffers from chronic back and leg pain. Patient needs to retrovert the pelvis and bend knees to have a horizontal gaze and compensate for loss of sagittal balance. Patient is known to have ankylosing spondylitis. 

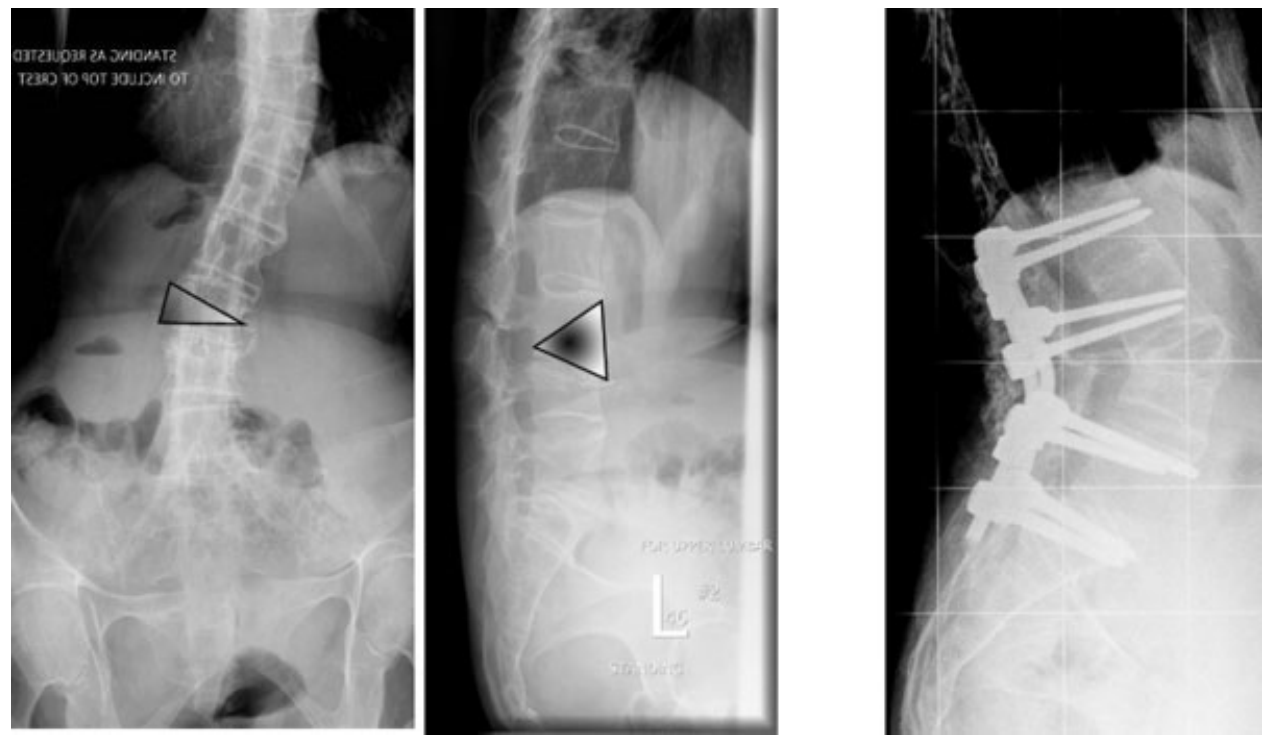

Fig. 5 Asymmetrical spinal osteotomy consisting of pedicle subtraction and opening wedge osteotomy performed at L3, correcting both coronal and sagittal plan deformity.

reasonable chance of success if there is a strong indication for surgery and if the patient is carefully selected.

- Patients with TLKDs secondary to AS should be screened prior to undergoing OWO due to the risk of life-threatening vascular injury resulting from the rupture of a calcified aorta. The authors feel that the incidence of this complication in association with OWO was minimized due to a strong selection bias. It follows that in patients with clinically significant atherosclerosis, the CWO may be a more appropriate procedure. The suggestion that OWOs may be more likely to cause serious complications when compared with CWOs is consistent with the views ex- pressed in a structured review of corrective spinal osteotomies in AS patients authored by Van Royen and De Gast (1999). ${ }^{21}$

\section{Funding}

Analytic support for this work was provided by Spectrum Research, Inc. with funding from AOSpine.

Conflict of Interest

None

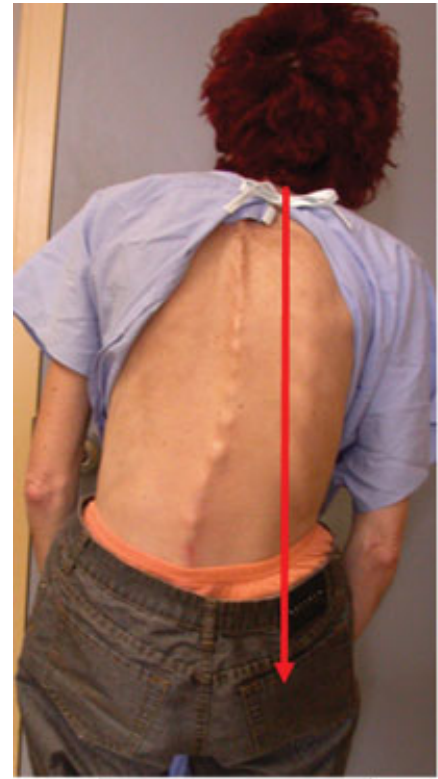

Pre OP
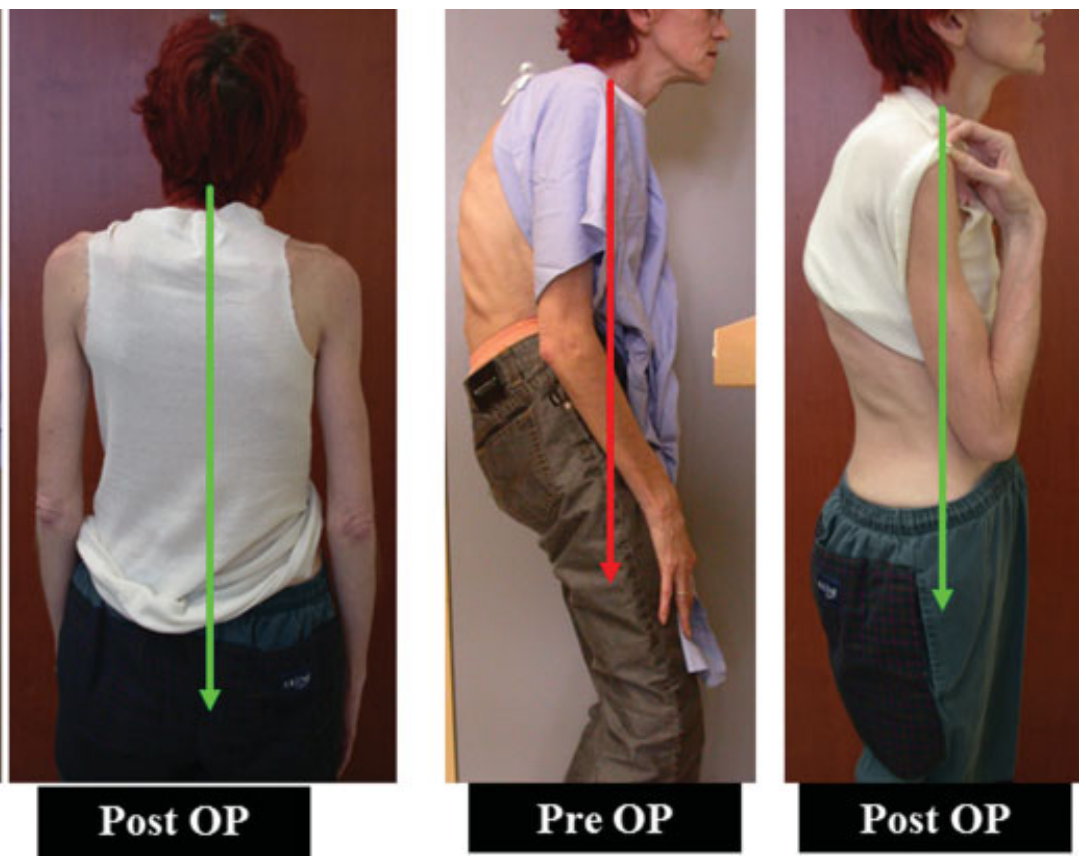

Fig. 6 Anatomical realignment achieved, sagittal and coronal balance restored. 

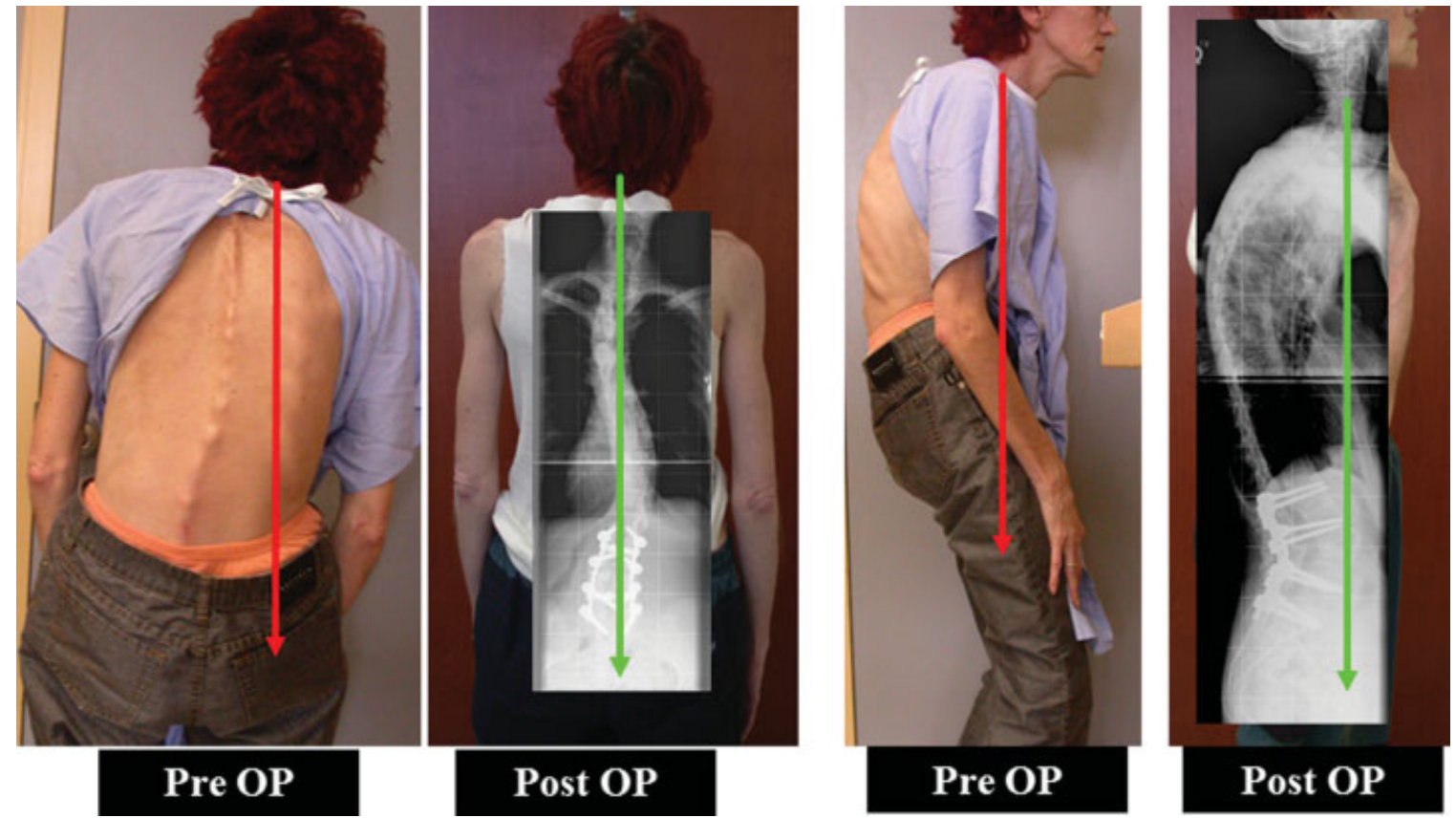

Fig. 7 Anatomical realignment achieved, sagittal and coronal balance restored.

\section{References}

1 Bossers GT. Columnotomy in severe Bechterew kyphosis. Acta Orthop Belg 1972;58(1):47-54

2 Chen PQ. Correction of kyphotic deformity in ankylosing spondylitis using multiple spinal osteotomy and Zielke's VDS instruments. Taiwan Yi Xue Hui Za Zhi 1988;87(7):692-699

3 Goel MK. Vertebral osteotomy for correction of fixed flexion deformity of the spine. J Bone Joint Surg Am 1968;50(2):287-294

4 Kubiak EN, Moskovich R, Errico TJ, Di Cesare PE. Orthopaedic management of ankylosing spondylitis. J Am Acad Orthop Surg 2005;13(4):267-278

5 McMaster MJ, Coventry MB. Spinal osteotomy in ankylosing spondylitis. Technique, complications, and long-term results. Mayo Clin Proc 1973;48(7):476-486

6 Simmons EH. Kyphotic deformity of the spine in ankylosing spondylitis. Clin Orthop Relat Res 1977;(128):65-77

7 Braun J, Brandt J, Listing J, Rudwaleit M, Sieper J. Biologic therapies in the spondyloarthritis: new opportunities, new challenges. Curr Opin Rheumatol 2003;15(4):394-407

8 Tak PP, Kalden JR. Advances in rheumatology: new targeted therapeutics. Arthritis Res Ther 2011;13(Suppl 1):S5

9 Berven SH, Deviren V, Smith JA, Emami A, Hu SS, Bradford DS. Management of fixed sagittal plane deformity: results of the transpedicular wedge resection osteotomy. Spine (Phila Pa 1976) $2001 ; 26(18): 2036-2043$

10 Chen IH, Chien JT, Yu TC. Transpedicular wedge osteotomy for correction of thoracolumbar kyphosis in ankylosing spondylitis: experience with 78 patients. Spine (Phila Pa 1976) 2001;26(16): E354-E360

11 Gill JB, Levin A, Burd T, Longley M. Corrective osteotomies in spine surgery. J Bone Joint Surg Am 2008;90(11):2509-2520

12 van Royen BJ, de Kleuver M, Slot GH. Polysegmental lumbar posterior wedge osteotomies for correction of kyphosis in ankylosing spondylitis. Eur Spine J 1998;7(2):104-110
13 Wright JG, Swiontkowski MF, Heckman JD. Introducing levels of evidence to the journal. J Bone Joint Surg Am 2003;85-A(1):1-3

14 West S, King V, Carey TS, et al. Systems to rate the strength of scientific evidence. Evidence Report/Technology Assessment No. 47 (prepared by the Research Triangle Institute-University of North Carolina Evidence-Based Practice Center, Contract No. 290-97-0011). Rockville, MD: Agency for Healthcare Research and Quality; 2002

15 Methods Guide for Effectiveness and Comparative Effectiveness Reviews. AHRQ Publication No. 10(12)-EHC063-EF. Rockville, MD. April 2012. Available at: www.effectivehealthcare.ahrq.gov

16 Atkins D, Best D, Briss PA, et al. GRADE Working Group. Grading quality of evidence and strength of recommendations. BMJ 2004;328(7454):1490

17 Arun R, Dabke HV, Mehdian H. Comparison of three types of lumbar osteotomy for ankylosing spondylitis: a case series and evolution of a safe technique for instrumented reduction. Eur Spine J 2011;20(12):2252-2260

18 Chang KW, Chen YY, Lin CC, Hsu HL, Pai KC. Closing wedge osteotomy versus opening wedge osteotomy in ankylosing spondylitis with thoracolumbar kyphotic deformity. Spine (Phila Pa 1976) 2005;30(14):1584-1593

19 Lazennec JY, Saillant G, Saidi K, et al. Surgery of the deformities in ankylosing spondylitis: our experience of lumbar osteotomies in 31 patients. Eur Spine J 1997;6(4):222-232

20 Zhu Z, Wang X, Qian B, et al. Loss of correction in the treatment of thoracolumbar kyphosis secondary to ankylosing spondylitis: a comparison between Smith-Petersen osteotomies and pedicle subtraction osteotomy. J Spinal Disord Tech 2012;25(7): 383-390

21 Van Royen BJ, De Gast A. Lumbar osteotomy for correction of thoracolumbar kyphotic deformity in ankylosing spondylitis. A structured review of three methods of treatment. Ann Rheum Dis 1999;58(7):399-406 


\section{Editorial Perspective}

The current study by Ravinsky et al attempted to investigate the differences between opening wedge osteotomy (OWO) and closing wedge osteotomy (CWO) in patients with ankylosing spondylitis (AS) suffering from severe thoracolumbar kyphosis with respect to quality-of-life assessments, complication risks, and the amount of correction of the spine achieved at follow-up. However, no statistically significant differences were seen in patient-reported or radiographic outcomes between these two techniques according to the results of this study. In consideration of the low level of the evidence, the authors have low confidence that the evidence reflects the true effect. These procedures-and the patient cohort they are trying to treat-are highly complex and complication prone. There was unanimous concern that the quoted literature actually underreported true complication rates and did not have sufficient long-term reporting to reflect the reoperation rate of these patients accurately.

The reviewer noted some further questions and concerns:

In ankylosing spondylitis, the location of kyphosis and "geography" of the curve plays a big role in the surgical planning. This may impact the location of an osteotomy, meaning that not all osteotomies will take place in the mid-lumbar spine; some will be best performed at the thoracolumbar junction, others in the thoracic spine, yet others at the cervicothoracic junction. This systematic review did not (or could not?) address the location of osteotomies and its effect on complications. For example, Did thoracic level osteotomies have more complications than lumbar level procedures regardless of type of osteotomy?

In ankylosing disorders, there are a number of factors that lead to kyphosis beyond the disease process itself. There are, for instance, nonoperatively treated fractures, which usually heal in kyphosis. Osteoporosis or hip flexion contractures may also significantly affect sagittal balance and may certainly impact the alignment profile of patients with ankylosing spondylitis. Finally, there are conditions such as "sterile discitis" or nonhealed areas in ankylosing spondylitis that may induce kyphosis and influence decision making as to osteotomies or need for inclusion in a corrective procedure. Aside from the level of an osteotomy, the underlying pathology would significantly affect the decision-making process for any reconstructive surgery. The present systematic review does not address such underlying pathologies.

The authors explicitly excluded multilevel osteotomies. This was done with the intent to provide the highest possible statistical purity. However, surgical technique issues may have also played a role in complications. How did constructs affect the outcomes? For instance, did all-screw constructs have less complications than hook, Luque sublaminar cable, or hybrid constructs? Did OWO require supplemental anterior fusions, or if not, did they lose reduction over time?

In terms of curve correction, do the kyphosis angles truly matter, or should we be more concerned with restoration of sagittal and coronal balance? There still seems to be an increased focus on local restoration of the alignment rather than attention to the global spinal alignment.

The authors deserve a lot of praise for raising our awareness to the problems, which we face in patients with ankylosing spondylitis. From this review, it seems clear that there is not a simple or clearly preferable answer for surgical reconstruction in patients with ankylosing spondylitis suffering from clinically significant TLKDs resulting in loss of sagittal balance. The Editors of EBSJ recommend more comprehensive data gathering from a large surgeon body such as AOSpine to allow us a more differentiated analysis of the outcomes and complications of these complex procedures. 